\title{
Pattern of Structural Heart Disease and Predictors of Mortality Among Affected Children Seen at the Niger Delta University Teaching Hospital Bayelsa State
}

\author{
Chika Onyinyechi Duru ${ }^{1,}$, Immaculata Ima Tunde-Oremodu², Onyaye Kunle-Olowu ${ }^{1}$ \\ ${ }^{1}$ Department of Paediatrics, Faculty of Clinical Sciences, Niger Delta University, Amassoma, Bayelsa State, Nigeria \\ ${ }^{2}$ Department of Paediatrics, Federal Medical Centre, Yenagoa, Bayelsa State, Nigeria
}

Email address:

duru_chika@yahoo.com (C. O. Duru)

${ }^{*}$ Corresponding author

To cite this article:

Chika Onyinyechi Duru, Immaculata Ima Tunde-Oremodu, Onyaye Kunle-Olowu. Pattern of Structural Heart Disease and Predictors of Mortality Among Affected Children Seen at the Niger Delta University Teaching Hospital Bayelsa State. Cardiology and Cardiovascular Research. Vol. 4, No. 2, 2020, pp. 71-79. doi: 10.11648/j.ccr.20200402.17

Received: April 21, 2020; Accepted: May 8, 2020; Published: May 28, 2020

\begin{abstract}
Paediatric structural heart diseases are an important cause of morbidity and mortality especially in developing countries where late presentation and delayed diagnosis and treatment is common. The aim of this study was to describe the pattern of structural heart diseases in children seen in the Paediatric Cardiology Unit of a tertiary hospital in Bayelsa State Nigeria and identify the predictors of mortality among those who died over the study period. It was a retrospective review of cases seen in the paediatric cardiology unit and subsequently followed up over a 7-year period ( $1^{\text {st }}$ April 2013 to $31^{\text {st }}$ March 2020). Sociodemographic data, clinical features and echocardiographic findings as well as details of their outcome were documented. Data was imputed into an Excel spread sheet and analyzed using SPSS 22.0. Binary logistic regression was performed to determine the risk factors for mortality. Of the 175 children seen by the Cardiology Unit over the study period, 92 (52.6\%) had structural heart diseases. The mean age of the children was 39.4 \pm 56.2 months with a male: female ratio of 1.6:1. Congenital heart diseases (CHD) were noted in $92 \%$ of cases with Atrial septal defects (ASD), followed by Ventricular Septal defects (VSD) and Patent Ductus Arteriosus (PDA) being the most prevalent CHD seen. The combination of ASD/VSD/PDA was the most common multiple structural defect noted. Acquired heart diseases including Rheumatic heart disease and Dilated cardiomyopathy were reported in $8 \%$ of cases. Mortalities were recorded in 20 children $(21.7 \%)$ with most of the deaths occurring as a result of intractable heart failure. Mortality was significantly associated with the third birth order (OR-4.63; p$0.021)$, fast breathing (OR-2.15; p-0.006), presence of heart failure (OR-3.16; $\mathrm{p}-0.026)$, failure to thrive (OR-2.93; $\mathrm{p}-0.036)$, use of cardiac medications (OR-6.91; 0.0013) and CHD with multiple structural defects (OR-11.44; p-0.006).
\end{abstract}

Keywords: Structural Heart Disease, Children, Bayelsa, Predictors, Mortality

\section{Introduction}

Structural heart diseases are congenital or acquired heart diseases affecting the heart $[1,2]$. In children, they could be detected at birth; as congenital heart diseases or acquired later in childhood. Congenital heart diseases (CHD) have been reported to occur in about 4 to 12 per 1000 live births worldwide and constitute a significant proportion of structural heart diseases described $[1,2]$. CHD are the most common underlying causes of mortality in children with congenital birth defects and accounted for $4 \%$ of childhood mortality worldwide in 2010 [1-3].

The pattern of structural cardiac anomalies seen vary depending on whether they are congenital or acquired in origin. Though regional and geographic differences in prevalences of CHD has been largely described, most studies done across the country demonstrate that "mild" structural defects such as ventricular septal defects, atrial septal defects and patent ductus arteriosus are the commonest CHD [4-9]. Concerning acquired heart disease, rheumatic heart disease and dilated cardiomyopathy still remain common causes of acquired heart disease in Nigeria 
closely followed by myocarditis and pericarditis [9-12]. Rheumatic heart disease (RHD), though reported to be on the downward trend globally, still remains a public health problem in low and middle income countries like ours where adequate preventive practices against rheumatic fever are yet to be fully implemented [13].

In Nigeria and other developing countries, mortality from structural heart diseases remains higher than in developed countries because most affected children present late $[8,13]$. Late presentation and subsequent delay in diagnosis of cardiac diseases occurs due to various reasons such as paucity of neonatal cardiac screening, non-inclusion of cardiac services under the national health insurance scheme and high out of pocket expenditures incurred by the parents of the child with cardiac disease [13-16]. These children usually present with severe complications such as failure to thrive, severe heart failure and irreversible pulmonary hypertension with Eisenmengers syndrome which may lead to inoperability or death of the child before lifesaving catheter or surgical interventions can be instituted [13]. This is unlike what occurs in developed countries where cardiac conditions are detected at birth and promptly managed, thus reducing mortality $[1,2,17]$.

With increased availability of paediatric cardiology services in Nigeria, there has been an upscaling in the diagnosis of paediatric heart diseases using paediatric echocardiography in many centres in Nigeria [18]. Echocardiography is a safe, painless, non-invasive and reliable method for cardiac diagnosis of structural heart diseases [19]. Its accessibility and ease of use in children from the neonatal period to late childhood and adolescence makes it an important clinic tool for any cardiologist in making a definitive diagnosis. With the introduction of echocardiography services, children presenting to the paediatric department with symptoms of cardiac disease are able to have a definitive diagnosis for their cardiac condition [13]. Early diagnosis and prompt commencement of treatment in affected children could possibly prolong survival in affected children.

The aim of this study was thus to describe the pattern of structural heart diseases seen in the paediatric cardiology unit and describe the predictors of mortality among those with cardiac diseases seen in a tertiary hospital in the Niger Delta region of Nigeria.

\section{Materials and Methods}

\subsection{Study Design}

This was a retrospective study conducted at the pediatric cardiology unit of the Niger Delta University Teaching Hospital (NDUTH), a tertiary health care centre in Okolobiri a semi urban community in Bayelsa State. The NDUTH is a state owned tertiary health care institution which commenced operations in 2007, and serves Bayelsa State and other neighboring states in the Niger delta region. The Paediatric department has a Children's Emergency ward, Children's ward, Special Care Baby unit and Outpatient clinics. The Paediatric Cardiology clinic is a weekly clinic where patients with symptoms suggestive of cardiac disease are attended to by a foreign trained Paediatric Cardiologist. Children with suspected cases of congenital or acquired heart disease admitted into any of the other wards of the department are also seen by the Paediatric Cardiologist.

\subsection{Conduct of the Study}

For each patient, following a detailed history, thorough physical examination and ancillary tests such as a chest radiograph and electrocardiograph, a transthoracic echocardiogram was usually requested for. Both the standalone machine (Accuson Siemens) and a portable machine (Esaote Gamma) with 2-D, M-mode and Colour doppler capabilities and fitted with cardiac probes of appropriate frequencies were used by one operator (the first author). The performance of the transthoracic echocardiogram involved placing the child in a supine or left lateral position where appropriate and placing the probe in the four main cardiac windows: subcostal, suprasternal, apical and parasternal to delineate the cardiac structures. M-mode was employed to take appropriate structural measurements while the Colour doppler was used to delineate direction and magnitude of flows across valves and shunts and determine pressure gradients where necessary. Agitated children and those less than 1 year old were sedated with oral chloral hydrate at $50 \mathrm{mg} / \mathrm{kg} / \mathrm{dose}$ while older children were calmed by their parents. Following the completion of the echocardiography scan, there was a counselling session with the Paediatric cardiologist where the diagnosis was explained to the parents and /or the child if over the age of 7 years. The counselling session was aided by a cardiac model and drawings on a paper where the Paediatric cardiologist explained the diagnosis, complications of the cardiac condition, prevention of infective endocarditis, prognosis and need if so, for medical and/or surgical treatment. Finally, appropriate medications were prescribed for the patient with request for an initial 2 weekly follow-up visit.. Those with cardiac lesions in need of urgent surgical intervention were promptly referred to cardiac surgical centres in the country or abroad where available

\subsection{Data Collection}

Details of all paediatric cardiology cases seen over a 7 year period- $1^{\text {st }}$ April 2013 to $31^{\text {st }}$ March 2020 were prospectively recruited by inputing their details into an Excel spreadsheet after each consultation. Information such as the age, sex, socioeconomic status, age at diagnosis, presenting complaints, birth order, pregnancy/birth history, associated comorbidities, echocardiographic diagnosis, medication use and outcome were noted. Following the history, examination findings and echocardiographic diagnosis [19] structural heart lesions were classified into congenital heart diseases (CHD) or acquired heart diseases (AHD). CHD were further divided 
into acyanotic or cyanotic CHD depending on the presence or absence of hypoxaemia determined by an oxygen saturation using a pulse oximeter (NONIN 909) with $92 \%$ set as the cut-off point. Structural defects were categorized as 'single' and 'multiple' depending the number of defects present in each child. Outcome of care in the period under review was classified as 'alive' and 'dead'. Socioeconomic status was determined using the Oyedeji socioeconomic classification [20].

\subsection{Data Analysis}

Categorical variables were summarized as frequencies and percentages, while descriptive statistics like mean, median, standard deviation and range were calculated for continuous variables. Predictors of mortality among the children were identified by binary logistic regression. The dependent variable 'outcome of care' was dichotomized by coding 'alive' as ' 1 ' and otherwise was coded as ' 0 '. Independent variables like age, sex, birth order, complications, comorbidity, intervention etc. were thereafter tested with the dependent variable in a regression analysis to generate odd ratio for each independent variable. All analyses were conducted with SPSS version 22 and p-Values $<0.05$ were considered significant.

\subsection{Ethical Considerations}

Ethical approval was obtained from the Research and Ethics Review Committee of the NDUTH before commencement of the study.

\section{Results}

Ninety-two (92) children with structural heart disease were seen over the study period. Their ages ranged from 0.25 to 204 months with a mean age of $39.4 \pm 56.2$ months. Of the 92 children, $57(62.0 \%)$ were male while 35 (38.0\%) were female giving a male to female ratio of 1.6: 1 (Table 1). Most of the children were infants $(58.7 \%)$, belonged to the high socioeconomic class $(51.1 \%)$ and were first born children $(44.6 \%)$ in the family. The median birth order was 2 with a range of $1-7$ (Table 1 ).

Table 2 shows that the most common presenting complaints were fast breathing $(53.3 \%)$, failure to thrive $(29.3 \%)$, cough and Incidental murmur $(18.5 \%$ each) while tachypnea $(28.3 \%)$, tachycardia $(14.1 \%)$ and tender hepatomegaly $(9.8 \%)$ were the most demonstrated clinical signs on examination. Most of the affected children presented within the first 6 months of onset of symptoms though the mean duration of presenting symptoms was $11.2 \pm 23.3$ months.

Table 1. Sociodemographic characteristics of Children in the study.

\begin{tabular}{lll}
\hline Characteristics & Frequency $(\mathbf{N}=92)$ & Percentage (\%) \\
\hline Sex & & \\
Male & 57 & 62.0 \\
Female & 35 & 38.0 \\
\hline
\end{tabular}

\begin{tabular}{lll}
\hline Characteristics & Frequency $(\mathbf{N}=92)$ & Percentage (\%) \\
\hline Age Group & & \\
$0-11$ months & 54 & 58.7 \\
$12-59$ months & 13 & 14.1 \\
$60-143$ months & 17 & 18.5 \\
$\geq 144$ months & 8 & 8.7 \\
Child socioeconomic class & & \\
Low SES & 17 & 18.5 \\
Middle SES & 28 & 30.4 \\
High SES & 47 & 51.1 \\
Birth Order & & \\
1 & 41 & 44.6 \\
2 & 22 & 23.9 \\
3 & 14 & 15.2 \\
4 & 8 & 8.7 \\
$\geq 5$ & 7 & 7.6 \\
\hline
\end{tabular}

Table 2. Presenting Complaints of Children with Cardiac disease.

\begin{tabular}{|c|c|c|}
\hline Characteristics & Frequency $(\mathrm{N}=92)$ & Percentage (\%) \\
\hline \multicolumn{3}{|l|}{ Presenting Complaint* } \\
\hline Fast breathing & 49 & 53.3 \\
\hline Failure to thrive & 27 & 29.3 \\
\hline Cough & 17 & 18.5 \\
\hline Incidental murmur & 17 & 18.5 \\
\hline Cyanosis & 13 & 14.1 \\
\hline Easy fatiguability & 11 & 12.0 \\
\hline Prematurity & 8 & 8.7 \\
\hline Downs facies & 8 & 8.7 \\
\hline Palpitation & 7 & 7.6 \\
\hline Fever & 7 & 7.6 \\
\hline Squatting & 5 & 5.4 \\
\hline Chest pain & 4 & 4.3 \\
\hline Fainting spells & 2 & 2.2 \\
\hline Others** & 10 & 10.9 \\
\hline \multicolumn{3}{|c|}{ Duration of presenting complaint } \\
\hline$<1$ month & 27 & 29.3 \\
\hline $1-6$ months & 30 & 32.6 \\
\hline $7-12$ months & 15 & 16.3 \\
\hline $13-59$ months & 14 & 15.2 \\
\hline$\geq 60$ months & 6 & 6.5 \\
\hline \multicolumn{3}{|c|}{ * Physical examination Findings } \\
\hline Tachypnea & 26 & 28.3 \\
\hline Tachycardia & 13 & 14.1 \\
\hline Tender hepatomegaly & 9 & 9.8 \\
\hline Cyanosis & 7 & 7.6 \\
\hline Dysmorphic features & 5 & 5.4 \\
\hline Small for age & 3 & 3.3 \\
\hline Pallor & 2 & 2.2 \\
\hline Digital clubbing & 2 & 2.2 \\
\hline
\end{tabular}

* some had more than one presenting complaint and physical examination finding on examination.

* * Others include Excessive sweating, Hypertension, Diarrhoea/Vomiting,

Leg swelling, Abdominal pain.

Table 3 shows that most of the children were the product of normal pregnancy $(58.7 \%)$ but $3.3 \%$ were conceived by assisted reproductive technology (In-vitro fertilization). Prematurity was the most common complication of pregnancy $(13.0 \%)$. There was no history of consanguinity in 
any of the cases seen.

Most of the heart disease existed as a single structural lesion; $55(59.8 \%)$, while $37(40.2 \%)$ involved multiple structural defects. Congenital heart diseases accounted for the majority; 85 (92.4\%) of the cardiac disease while acquired heart diseases accounted for 7 (7.6\%) of cases. HIV/TB $(8.7 \%)$, Down syndrome $(7.6 \%)$ and SCD $(7.6 \%)$ were the commonest comorbid conditions noted (Table 4).

As shown in Table 4, Atrial septal defect (ASD) was the commonest acyanotic congenital heart diseases seen in 40 (43.5\%) followed by Ventricular septal defect (VSD) in 29 (31.5\%), and Patent ductus arteriosus (PDA) in 20 (21.7\%) children. All three (ASD, VSD. PDA) were also the commonest defects noted in combination in those with multiple structural lesions (Table 5). Tetralogy of Fallot was the commonest cyanotic congenital heart diseases noted in 6 $(6.5 \%)$ children followed by Transposition of the Great arteries in $4(4.3 \%)$ children. Only two cases of Acquired heart diseases (Rheumatic heart diseases and HIV dilated cardiomyopathy) were documented in the study (Table 4)
Table 3. Pregnancy and Family history of Children with cardiac disease.

\begin{tabular}{lll}
\hline Characteristics & $\begin{array}{l}\text { Frequency } \\
(\mathbf{N = 9 2 )}\end{array}$ & $\begin{array}{l}\text { Percentage } \\
(\mathbf{\%})\end{array}$ \\
\hline Pregnancy History & & \\
Normal Uneventful Pregnancy & 54 & 58.7 \\
History of complications & 38 & 41.3 \\
History of Consanguinity & & \\
Yes & 0 & 0.0 \\
No & 92 & 100.0 \\
Mode of Conception & & \\
Normal & 89 & 96.7 \\
IVF & 3 & 3.3 \\
* Condition complicating Pregnancy & & \\
Prematurity & 12 & 13.0 \\
Diabetes mellitus & 3 & 3.3 \\
Hypertension & 3 & 3.3 \\
Multiple gestation & 3 & 3.3 \\
Alcohol/Herbal Concoction Ingestion & 3 & 3.3 \\
Asthma & 1 & 1.1 \\
\hline
\end{tabular}

* Some had more than one condition.

Table 4. Pattern of Cardiac disease seen in the 92 children.

\begin{tabular}{|c|c|c|}
\hline Characteristics & Frequency $(\mathrm{N}=92)$ & Percentage (\%) \\
\hline \multicolumn{3}{|l|}{ Number of Cardiac structural defect } \\
\hline Single structural defect & 55 & 59.8 \\
\hline Multiple structural defect & 37 & 40.2 \\
\hline \multicolumn{3}{|l|}{ Type of Cardiac disease } \\
\hline Congenital heart disease & 85 & 92.4 \\
\hline Acquired heart disease & 7 & 7.6 \\
\hline \multicolumn{3}{|l|}{ Type of Congenital heart disease $(n=85)$} \\
\hline Acyanotic cardiac disease & 71 & 83.5 \\
\hline Cyanotic cardiac disease & 14 & 16.5 \\
\hline \multicolumn{3}{|l|}{ Cardiac Conditions* } \\
\hline \multicolumn{3}{|l|}{ Congenital heart disease } \\
\hline Atrial Septal defect & 40 & 43.5 \\
\hline Ventricular septal defect & 29 & 31.5 \\
\hline Patent ductus arteriosus & 20 & 21.7 \\
\hline Atrioventricular septal defect & 7 & 7.6 \\
\hline Tetralogy of Fallot & 6 & 6.5 \\
\hline Pulmonary Stenosis & 6 & 6.5 \\
\hline Transposition of Great Arteries & 4 & 4.3 \\
\hline Dextrocardia & 4 & 4.3 \\
\hline Others** & 15 & 16.3 \\
\hline \multicolumn{3}{|l|}{ Acquired heart diseases } \\
\hline Rheumatic heart disease & 6 & 6.5 \\
\hline HIV dilated cardiomyopathy & 1 & 1.1 \\
\hline \multicolumn{3}{|l|}{ Comorbidity Present } \\
\hline Yes & 25 & 25.8 \\
\hline No & 67 & 74.2 \\
\hline \multicolumn{3}{|l|}{ Comorbidity* } \\
\hline Human Immunodeficiency Virus/Tuberculosis (HIV/TB) & 8 & 8.7 \\
\hline Down's syndrome & 7 & 7.6 \\
\hline Sickle cell disease (SCD) & 7 & 7.6 \\
\hline Congenital anomaly & 2 & 2.2 \\
\hline Malignancy & 2 & 2.2 \\
\hline Congenital rubella syndrome & 1 & 1.1 \\
\hline
\end{tabular}

*more than one option is applicable.

**Others include Tricuspid atresia, Pulmonary atresia, Double outlet ventricle, Double inlet ventricle,, Cor Triatriatum dextrum, Atrial septum aneurysm. 
Table 5. Pattern of Congenital heart diseases seen in the 85 children with CHD.

\begin{tabular}{|c|c|c|c|c|c|c|c|}
\hline \multicolumn{4}{|c|}{ Acyanotic congenital heart disease $(n=71)$} & \multicolumn{4}{|c|}{ Cyanotic congenital heart disease $(n=14)$} \\
\hline Single lesion & $n=45$ & Multiple lesions & $n=26$ & Single lesion & $n=10$ & Multiple lesions & $n=4$ \\
\hline ASD & 18 & $\mathrm{ASD} / \mathrm{VSD} / \mathrm{PDA}$ & 6 & TOF & 4 & TOF/PDA & 1 \\
\hline VSD & 15 & ASD/PDA & 6 & d-TGA & 2 & $\mathrm{DC} /$ single atrium/ $\mathrm{MR}$ & 1 \\
\hline AVSD & 4 & ASD/VSD & 5 & DORV & 1 & $\begin{array}{l}\text { d-TGA/ASD/BAV/ Cor } \\
\text { Triatriatum dextum }\end{array}$ & 1 \\
\hline PDA & 3 & $\mathrm{ASD} / \mathrm{PS}$ & 2 & DILV & 1 & TOF/ASD & 1 \\
\hline DC & 2 & AVSD/PDA & 2 & cc-TGA & 1 & & \\
\hline Atrial septal aneurysm & 2 & AVSD/ASD & 1 & Tricuspid atresia & 1 & & \\
\hline \multirow{4}{*}{ Cor Triatriatum dextum } & 1 & VSD/PS & 1 & & & & \\
\hline & & VSD/PDA & 1 & & & & \\
\hline & & $\mathrm{PDA} / \mathrm{COA}$ & 1 & & & & \\
\hline & & ASD/Cor Triatriatum dextum & 1 & & & & \\
\hline
\end{tabular}

Note: ASD- Atrial Septal Defect, VSD-Ventricular Septal Defect, AVSD-Atrioventricular Septal Defect, PDA-Patent Ductus Arteriosus, TOF- Tetralogy of Fallot, DORV- Double Outlet Right Ventricle, DILV-Double Inlet Left Ventricle, d-TGA-dextro Transposition of the Great Arteries, cc-TGA-congenitally corrected Transposition of the Great Arteries, PS-Pulmonary Stenosis, BAV-Bicuspid Aortic Valve, DC-Dextrocardia, COA- Coarctation of the Aorta, MRMitral regurgitation, RHD- Rheumatic heart disease, DCM- Dilated Cardiomyopathy.

Table 6. Management, Outcome and Complications of Heart Diseases among study participants.

\begin{tabular}{lll}
\hline Characteristics & Frequency (N=92) & Percentage (\%) \\
\hline Medical Management* & & \\
No medications & 29 & 31.5 \\
Anti-failure medications & 54 & 58.7 \\
Propanolol & 7 & 7.6 \\
Sildenafil & 5 & 5.4 \\
Complications* & & \\
Failure to thrive & 28 & 29.3 \\
Heart failure & 14 & 15.2 \\
Tet spells & 4 & 4.3 \\
Pulmonary hypertension & 3 & 3.3 \\
Surgical Intervention & & \\
Yes & 15 & 16.3 \\
No & 77 & 83.7 \\
Outcome of care & & \\
Alive & 72 & 78.3 \\
Died & 20 & 21.7 \\
Causes of death (n=20) & & \\
Heart failure & 13 & 65.0 \\
Arrhythmias & 3 & 15.0 \\
Infective endocarditis & 2 & 10.0 \\
Non-accidental injury & 1 & 5.0 \\
Post-surgical complications & 1 & 5.0 \\
\hline
\end{tabular}

*More than one option is applicable.

About a third of the children (31.5\%) were managed without medication, while more than half were commenced on anti-failure medication (58.7\%) for their symptoms. Failure to thrive $(29.3 \%)$ and heart failure $(15.2 \%)$ were the most common complications among the study population (Table 6).

Fifteen (16.3\%) children had a surgical or catheter intervention for their cardiac defect which included total intracardiac repair which was carried out in 12 children, Glenn shunt and Blalock Taussig shunt performed in 1 child each and Catheter intervention for PDA closure and aortopulmonary coil embolization in 2 children. Over the study period, a fifth $(21.7 \%)$ of the children died with heart failure being a secondary cause of death in the majority (65.0\%) (Table 6).

Table 7 presents the results of binary logistic regression which identified factors associated with mortality among children managed for heart disease in NDUTH. Of the sociodemographic characteristics of the children, only the birth order of the child showed a significant relationship with mortality. The third-born child had a statistically significant increased odds of mortality (OR $-4.63 ; \mathrm{p}-0.021$ ) when compared to the first born child. Other birth positions except the fourth position showed similar relationship, however, this relationship was not statistically significant $(\mathrm{p}>0.05)$. Children with fast breathing $(\mathrm{OR}-2.15, \mathrm{p}-0.006)$ and with associated failure to thrive (OR $-2.93 ; \mathrm{p}-0.036)$ are more likely to die when considered in relation to children without these conditions. There was a significant increase in mortality in children whose cardiac disease was complicated by heart failure (OR - 3.16; p - 0.026) and those on cardiac medication for the management of their heart disease (OR 6.91; p- 0.013). Congenital heart disease associated with three structural cardiac defects significantly increased the odds of dying in children compared to children with single cardiac structural defect (OR - 11.44; p-0.006). However, children who were able to obtain the needed surgery for their condition had a reduced likelihood of death, though this was not statistically significant (OR - $-0.12 ; \mathrm{p}>0.866$ ).

Table 7. Predictors of mortality in children with Cardiac disease in NDUTH.

\begin{tabular}{|c|c|c|c|c|c|}
\hline \multirow{2}{*}{ Characteristics (Reference group) } & \multirow{2}{*}{ B coefficient } & \multirow{2}{*}{ OR } & \multicolumn{2}{|c|}{$95 \%$ CI } & \multirow{2}{*}{ p-Value } \\
\hline & & & Min & Max & \\
\hline Age & -0.01 & 0.99 & 0.98 & 1.01 & 0.220 \\
\hline Duration of disease & -0.02 & 0.98 & 0.94 & 1.02 & 0.289 \\
\hline Sex (Male) & & & & & \\
\hline
\end{tabular}




\begin{tabular}{|c|c|c|c|c|c|}
\hline \multirow{2}{*}{ Characteristics (Reference group) } & \multirow{2}{*}{ B coefficient } & \multirow{2}{*}{ OR } & \multicolumn{2}{|c|}{$95 \% \mathrm{CI}$} & \multirow{2}{*}{ p-Value } \\
\hline & & & Min & Max & \\
\hline Female & 0.20 & 1.22 & 0.46 & 3.24 & 0.696 \\
\hline \multicolumn{6}{|l|}{ Birth Order (First Born) } \\
\hline Second & 0.11 & 1.11 & 0.29 & 4.28 & 0.876 \\
\hline Third & 1.53 & 4.63 & 1.27 & 16.92 & $0.021^{*}$ \\
\hline Fourth & -0.28 & 0.76 & 0.08 & 7.13 & 0.806 \\
\hline Fifth & 0.75 & 2.11 & 0.34 & 13.15 & 0.422 \\
\hline \multicolumn{6}{|l|}{ Child Socioeconomic class (Low) } \\
\hline Middle & -0.52 & 0.59 & 0.15 & 2.40 & 0.465 \\
\hline High & 0.11 & 1.11 & 0.23 & 5.37 & 0.893 \\
\hline \multicolumn{6}{|l|}{ Fast Breathing (No) } \\
\hline Yes & 2.15 & 8.55 & 1.86 & 39.29 & $0.006^{*}$ \\
\hline \multicolumn{6}{|l|}{ Cough (No) } \\
\hline Yes & 0.51 & 1.67 & 0.51 & 5.42 & 0.396 \\
\hline \multicolumn{6}{|l|}{ Failure to thrive (No) } \\
\hline Yes & 1.08 & 2.93 & 1.07 & 8.01 & $0.036^{*}$ \\
\hline \multicolumn{6}{|l|}{ Cyanosis (No) } \\
\hline Yes & 0.98 & 2.66 & 0.77 & 9.21 & 0.123 \\
\hline \multicolumn{6}{|l|}{ Squatting (No) } \\
\hline Yes & 0.99 & 2.70 & 0.42 & 17.40 & 0.295 \\
\hline \multicolumn{6}{|l|}{ Comorbidity (No) } \\
\hline Yes & 0.13 & 1.14 & 0.37 & 3.52 & 0.816 \\
\hline \multicolumn{6}{|l|}{ Pulmonary Hypertension (No) } \\
\hline Yes & 0.62 & 1.85 & 0.16 & 21.45 & 0.623 \\
\hline \multicolumn{6}{|l|}{ Heart failure (No) } \\
\hline Yes & 1.15 & 3.16 & 1.15 & 8.68 & $0.026^{*}$ \\
\hline \multicolumn{6}{|l|}{ Medication (No) } \\
\hline Yes & 1.93 & 6.91 & 1.50 & 31.79 & $0.013^{*}$ \\
\hline \multicolumn{6}{|l|}{ Surgery (No) } \\
\hline Yes & -0.12 & 0.89 & 0.23 & 3.49 & 0.866 \\
\hline \multicolumn{6}{|c|}{ Number of structural defect (Single defect) } \\
\hline 2 defects & 0.22 & 1.22 & 0.23 & 2.83 & 0.729 \\
\hline$\geq 3$ Defects & 2.44 & 11.50 & 2.01 & 65.91 & $0.006^{*}$ \\
\hline
\end{tabular}

95\% CI - 95\% Confidence interval of OR; OR - Odd ratio; CHD - Congenital heart disease.

\section{Discussion}

In our study there was a male preponderance of cases with structural heart disease seen, This finding is similar to what has been reported by Abah et al [7] in Benue and Adebayo et al [9] in Ibadan. It however differs from reports by Zuechner et al [21] in Tanzania who reported a female predilection in their study. Different authors have reported varying sex predilections with respect to studies that involved congenital or acquired heart diseases. Ekure et al [8] in a large hospital based study reported an equal sex distribution among children with CHD in Lagos while Sadoh et al [10] in Benin and Sani et al [10] in Sokoto reported a male preponderance of cases of AHD in their studies. Though some authors have reported that there is no certainty that heart diseases affect one gender more than the other, [17] others have described significant sex differences among individual lesions [22].

The mean age of presentation was 3 years which is similar to the reported age of presentation in children within the first five years of life by other Nigerian authors [4-9]. This is to be expected as majority of the structural diseases in children are noted to be congenital heart diseases [4-9, 17]. In our study most of the children presented within the first six months of onset of their symptoms. This could be explained by the fact that most of the CHD were shunt lesions especially a combination of VSD, ASD and PDA. In the absence of prenatal screening by fetal echocardiography which is not readily available in Nigeria, most congenital heart diseases particularly those with shunt lesions present within the first three months of life as that is the time when pulmonary vascular resistance reaches its nadir thus resulting in the left to right shunting of blood with features of heart failure manifesting thus necessitating cardiac evaluation [17, 23]. It was not surprising that most of the children in our study presented with fast breathing and had tachypnea, tachycardia and tender hepatomegaly on examination, an observation which was also been previously described [6.7].

Unlike what has been reported by many other Nigerian authors, atrial septal defects (ASD) were the commonest congenital structural heart diseases noted in our study either as single lesions or in combination with other defects. Our findings are similar to reports by Sharifi et al [24] in Afghanistan who reported ASD as the commonest CHD in their study. Our findings are however at variance with what 
has been reported in other parts of Nigeria [4-10] as well as other parts of the world such as Tanzania [21], India [25], Cameroun [26] and Pakistan [27] where VSD was the commonest CHD in their studies. Abdulkadir et al in a systemic meta analysis on the pattern of CHD in Nigeria also reported VSD as the commonest lesion though he noted that the Northern part of Nigeria reported a predominance of other milder lesions such as ASD and PDA compared to the South [4]. The reason for this difference could be attributed to several ethnic and geographic factors which account for differences in the pattern of structural diseases in various regions of the country and world in general [1.4.27]. The diagnostic ability of the echocardiography to detect structural heart diseases postnatally coupled with the increased availability of paediatric cardiology services in Nigeria can attribute to the increased detection of these milder lesions as was postulated by Liu et al [1]. The preponderance of preterms in our study could also account for the presence of ASD and PDA which are usual fetal shunts which persist in the newborn.

Cyanotic congenital heart diseases accounted for just $8 \%$ of cases of CHD seen in the study among which Tetralogy of Fallot was the commonest lesion reported. This is similar to previous reports from other parts of Nigeria [5-10], Afghanistan [24] and India [25]. Cyanotic CHD are usually regarded as complex congenital heart diseases ranging in severity and usually leading to mortality in the early neonatal period in the absence of a lifesaving shunt for admixture of blood [28]. Apart from TOF, other complex congenital heart diseases, though few were reported in this study though there was no case of truncus arteriosus or Ebsteins anomaly. The low prevalence of complex CHD is surprising as the location of the hospital in the Niger Delta region of Nigeria increases the possibility of environmental causes of CHD due to the air and water pollution from oil spillage [29]. However, consanguinity which is a well recognized cause of complex CHD is quite rare in Nigeria which may also account for the low prevalence in the study area. Also the possibility that those with complex CHD died at birth or in early infancy is also another reason especially as most of the children in the study presented late.

Rheumatic heart disease and dilated cardiomyopathy were the only cases of AHD noted in our study. Both had similarly been described as the commonest AHD by authors from Nigeria [9-12] and other parts of Africa [21.30]. In our study, there was no case of Kawasaki disease, Endomyocardial fibrosis or Myocarditis which have been described in other studies [9-12] which may be due to the fewer cases noted in our study. Similar to CHD, variations in the prevalence of different types of AHD are common. The incidence of RHD which has been reported as the most prevalent AHD in most studies has been reported to be on the decline globally. This has been attributed to be due to improved living conditions, environmental sanitation and socioeconomic status in the developed countries [13, 30]. RHD however still remains a major public health concern in low and middle income countries where primary and secondary preventive measures for Acute rheumatic fever are yet to be fully adopted [13, 30].

In the present study, only about $20 \%$ of the children had surgical or catheter intervention for their cardiac diseases despite that fact that most were eligible for surgery. Low access to corrective surgery has also been reported by other Nigerian authors [6-9, 13-15, 22]. The inability of most Nigerians with structural heart diseases to access the much needed Surgery or Intervention arises from the high cost of surgical and catheter intervention, lack of inclusion of Cardiac surgery under the National Health Insurance Scheme and dependence on foreign aid in most cases [13-15]. The late presentation of most cases also results in some presenting with complications such as intractable heart failure and pulmonary hypertension which worsen morbidity and in some cases render them inoperable [13, 21].

A fifth of the children seen over the study period died. Mortality in the present study was significantly associated with the presence of heart failure and failure to thrive which were the major complications observed. In children, heart failure can present with respiratory distress, easy fatigability, effort intolerance and poor growth and is ultimately associated with significant morbidity and mortality [23]. These complications were similarly reported by other authors and was attributed to late presentation and delay in getting early and appropriate treatment in most cases $[6,7,28]$. Our study also reported a significant increase in mortality in those with multiple structural lesions. Onalo et al [28] in Nigeria, Rocha et al [31] in Brazil and Jortveit et al [32] in Norway in their studies similarly described an increased risk of mortality in children with complex CHD and associated comorbidities. The greater the number of lesions the more complex the heart disease is, and the greater risk for mortality.

The third born children were also noted to be significantly at risk of dying compared to other birth orders. The reason for this is not immediately clear, however it could be due to the economic burden of caring for a child with a cardiac disease in the presence of a large family size, thus leading to delays in presentation of the affected child and a greater chance of mortality $[16,33]$. The effect of large family size and increased fertility rates at the expense of the economy has been attributed to lead to an increased burden of CHD in countries with low incomes like ours [33]. Though not statistically significant, there was a reduced likelihood of death in those who were able to access surgical intervention as compared to those who could not. Massoure et al [34] in Djibouti in their study of a cohort of paediatric cardiology patients found a significant relationship between the failure to get surgery and increased risk of mortality. The timing of surgery for various paediatric cardiac diseases depends on the type and severity of the cardiac condition as reported by Chinawa et al [35] in Enugu. However, the earlier the access to corrective surgery, the greater the chances of survival in most cases as early intervention prevents and reduces the burden of postoperative morbidity and mortality. 


\section{Conclusion}

Congenital heart diseases were the prevalent structural heart diseases noted in our study of which Atrial Septal Defects was the commonest. They were mostly present in combination with VSD and PDA as multiple structural defects. Rheumatic heart disease was the most prevalent acquired heart disease detected. Mortality was significantly associated with the presence of heart failure, failure to thrive, cardiac medication use, multiple structural defects and birth order. Early detection and prompt intervention to reduce mortality from structural heart disease in children is recommended.

\section{References}

[1] Liu Y, Chen S, Zu"hlke L, Black GC, Choy M, Li N and Keavney BD. Global birth prevalence of congenital heart defects 1970-2017: updated systematic review and metaanalysis of 260 studies. International Journal of Epidemiology, 2019, 455-463.

[2] Hoffman J I. The global burden of congenital heart disease. Cardiovasc J Afr 2013; 24: 141-145.

[3] van der Linde D, Konings EEM, Slage MA, Witsenburg M, Helbing WA, Takkenberg JJM. Birth Prevalence of Congenital Heart Disease: A systemic Review and Meta-Analysis. $J$ Am Coll Cardiol 2011; 58: 2241-7.

[4] Abdulkadir M, Abdulkadir Z. A systematic review of trends and patterns of congenital heart disease in children in Nigeria from 1964-2015. Afr Health Sci 2016; 16 (2): 367-377.

[5] Asani M, Aliyu I, Kabir H. Profile of congenital heart defects among children at Aminu Kano Teaching Hospital, Kano, Nigeria. J Med Trop 2013; 15 (2): 131-134.

[6] Otaigbe BE, Tabansi PN. Congenital heart disease in the Niger Delta region of Nigeria: a four-year prospective echocardiographic analysis. Cardiovasc. J Afri 2014; 25 (6): 265-268.

[7] Abah RO, Ochoga MO, Audu OP, Idoko A, Eseigbe EE, Dabit JO. Pattern of cardiac diseases among children in a tertiary hospital in North Central, Nigeria: A three and half years retrospective cohort echocardiographic study. Niger $J$ Paediatr 2018; 45 (1): 6-9.

[8] Ekure EN, Kalu N, Sokunbi OJ, et al. Clinical epidemiology of congenital heart disease in Nigerian children, 2012-2017. Birth Defects Research. 2018; 1-8. https://doi.org/10.1002/bdr2.1361.

[9] Adebayo BE, Ogunkunle OO, Omokhodion SI, Luke RD. The spectrum of structural heart defects seen in children at the University College Hospital, Ibadan. Nig J Cardiol 2016; 13: 130-5.

[10] Sadoh E W, Uzodimma C C, Daniels Q. Childhood acquired heart disease in Nigeria: An echocardiographic study from three centres. Afr Health Sci 2014; 14 (3): 602-608.

[11] Sani UM, Ahmed H, Jiya NM. Pattern of acquired heart diseases among children seen in Sokoto, North Western Nigeria. Niger J Clin Pract 2015; 18: 718-25.
[12] Animasahun BA, Madise-Wobo AD, Kusimo OY. Nigerian Children with Acquired Heart Disease: The Experience in Lagos. J Teh Univ Heart Ctr 2017; 12 (4): 160-166.

[13] Bode-Thomas F. Overcoming Challenges in the Management of Structural Heart Diseases in Nigerian Children. J Med Trop 2011; 13: 3-10.

[14] Duru CO, Mesiobi-Anene N, Ujuanbi S, Akalonu E, Aliyu I, Akinbami F. Pattern and outcome of pediatric patients referred abroad for cardiac surgery from a tertiary hospital in the Niger Delta region of Nigeria. Nig J Cardiol 2018; 15: 9-13.

[15] Falase B, Sanusi M, Majekodunmi A, Ajose I, Idowu A, Oke $\mathrm{D}$, et al. The cost of open heart surgery in Nigeria. Pan Afr Med J 2013; 14: 61.

[16] Sadoh WE, Nwaneri DU, Owobu AC. The cost of out-patient management of chronic heart failure in children with congenital heart disease. Nig J Clin Pract 2011; 14 (1): 65-69.

[17] Cucu IA, Chifiriuc MC (2018) Congenital Heart Disease: Global Burden and Challenges to Eliminate Health Disparities. Ann Public Health Reports 2 (1): 26-29.

[18] Ekure EN, Sadoh WE, Bode-Thomas F, Orogade AA, Animasahun AB, Ogunkunle OO, et al. Audit of availability and distribution of Paediatric cardiology services and facilities in Nigeria. Cardiovasc J Afr 2016; 27.

[19] Lai WW, Geva T, Shirali GS, Frommelt PC, Humes RA, Brook $\mathrm{MM}$ et al. Guidelines and Standards for Performance of a Pediatric Echocardiogram: A Report for the Task Force of the Pediatric Council of the American Society of Echocardiography. $J$ Am Soc Echocardiogr 2006; 19: 1413-1430.

[20] Oyedeji GA. Socio-economic and Cultural background of Hospitalized children in Ilesha. Nig J Pediatr 1985; 12: 111117.

[21] Zuechner A, Mhada T, Majani NG, Sharau GG, Mahalu W, Freund MW. Spectrum of heart disease in children presenting to a paediatric cardiac echocardiography clinic in the Lake Zone of Tanzania: a 7 year overview. BMC Cardiovascular Disorders (2019) 19: $291 \mathrm{https://doi.org/10.1186/s12872-019-}$ 01292-4.

[22] Ekure EN, Bode-Thomas F, Sadoh WE, Orogade AA, Otaigbe BE, Ujunwa $F$, et al. Congenital Heart defects in Nigerian Children: Preliminary Data from the National Pediatric Cardiac Registry. World J Pediatr Congenit Heart Surg 2017; 8 (6): 699-706.

[23] Duru CO, Mesiobi-Anene N, Akinbami FO. Paediatric heart failure among emergency room admissions in a tertiary health centre in Southern Nigeria. Nig J Cardiol 2016; 13: 62-66.

[24] Sharifi AM. Pattern and frequency of pediatric congenital heart disease at the Cardiac Research Institute of Kabul Medical University, Afghanistan. Paediatr Indones 2018; 58: 106-109.

[25] Ingle VV. Profile of congenital heart disease in a semi urban and rural community: Two years' experience at a teaching hospital. International Journal of Medical and Health Research 2017; 3 (3): 75-78.

[26] Chelo D, Nguefack F, Menanga AP, Um SN, Gody JC, Tatah SA et al. Spectrum of heart diseases in children: an echocardiographic study of 1,666 subjects in a pediatric hospital, Yaounde, Cameroon. Diagn Ther 2016; 6 (1): 10-19. 
[27] Mohammed N, Shaikh S, Memon S, Das H. Spectrum of heart disease in children under 5 years of age at Liaquat university Hospital, Hyderabad, Pakistan. Indian Heart Journal 2014; 66: 145-149.

[28] Onalo R, Talatu Ajanaku I, Jibril A. Complex congenital heart defects in children in a resource constraint setting. $J$ Pediatr Neonat Individual Med. 2019; 8 (2): e080212. doi: $10.7363 / 080212$.

[29] Zhang B, Zhao Z, Zhao R, Qian Z, Liang S, Bassig BA, et al. Ozone and Other Air Pollutants and the Risk of Congenital Heart Defects. Sci. Rep. 6, 34852; doi: 10.1038/srep34852 (2016).

[30] Nkoke C, Menanga A, Boombhi J, Chelo D, Kingue S. A new look at acquired heart disease in a contemporary sub-Saharan African Paediatric population: The case of Yaounde, Cameroon. Cardiovasc Diagn Ther 2015; 5 (6): 428-434.

[31] Rocha LA, Froio SC, Silva CC, Figueira SA, Guilhen JCS, Guinsburg R et al. Risk Factors for Mortality in Children with Congenital Heart Disease Delivered at a Brazilian Tertiary Center. Braz J Cardiovasc Surg 2018; 33 (6): 603-607.
[32] Jortveit J, Eskedal L, Hirth A, Fomina T, Døhlen G, Hagemo P, Tell GS, Birkeland S, Øyen N, and Holmstrøm H. Sudden unexpected death in children with congenital heart defects. Eur Heart J 2016: 37; 621-626.

[33] GBD 2017 Congenital Heart Disease Collaborators Global, regional, and national burden of congenital heart disease, 1990-2017: a systematic analysis for the Global Burden of Disease Study 2017. Lancet Child Adolesc Health 2020; 4: 185-200.

[34] Massoure PL, Roche NC, Lamblin G, Dehan C, Kaiser E, Fourcade L. Cardiovascular disease in children in Djibouti: a single-centre study. Pan Afr Med J.09/04/2013; 14: 141. [doi: 10.11604/pamj.09/04/2013.14.141.2016].

[35] Chinawa JM, Adiele KD, Ujunwa FA, Onukwuli VO, Arodiwe I, et al. Timing of cardiac surgery and other intervention among children with congenital heart disease: A review article. J Cardiol Cardiovasc Med. 2019; 4: 94-99. 